\title{
Arctic Freshwater Ice and Its Climatic Role
}

\author{
Terry Prowse, Knut Alfredsen, Spyros Beltaos, Barrie Bonsal, \\ Claude Duguay, Atte Korhola, Jim McNamara, Warwick F. Vincent, \\ Valery Vuglinsky, Gesa A. Weyhenmeyer
}

\begin{abstract}
Freshwater ice dominates the Arctic terrestrial environment and significantly impacts bio-physical and socio-economic systems. Unlike other major cryospheric components that either blanket large expanses (e.g., snow, permafrost, sea ice) or are concentrated in specific locations, lake and river ice are interwoven into the terrestrial landscape through major flow and storage networks. For instance, the headwaters of large ice-covered rivers extend well beyond the Arctic while many northern lakes owe their genesis to broader cryospheric changes. The effects of freshwater ice on climate mostly occur at the local/regional scale, with the degree of influence dependent on the magnitude, timing, location, and duration of ice cover, and the size of the water body. Freshwater-ice formation, growth, decay, and break-up are influenced by climatic variables that control surface heat fluxes, but these differ markedly between lakes and rivers. Despite the importance of freshwater ice, there has been a recent reduction in observational recordings.
\end{abstract}

Keywords Lake ice $\cdot$ River ice $\cdot$ Climate $\cdot$ Cryosphere Arctic

\section{INTRODUCTION}

This report provides an introduction to Arctic freshwater ice including its climatic role. It sets the stage for two companion articles in this journal issue (Callaghan et al. 2011), which present the results of an international assessment of arctic lake and river ice conducted by the Arctic Monitoring and Assessment Program, SWIPA project (Snow, Water, Ice,

Electronic supplementary material The online version of this article (doi:10.1007/s13280-011-0214-9) contains supplementary material, which is available to authorized users.
Permafrost in the Arctic) (AMAP 2011). The subsequent two papers review the paleo-historical, instrumental, and projected future changes in Arctic lake and river-ice regimes (Prowse et al. 2011a [this issue]), and the effects of such changes on ecological, hydrological, and socio-economic systems (Prowse et al. 2011b [this issue]).

\section{ARCTIC FRESHWATER ICE}

Unlike the other major global cryospheric components of the Arctic that either blanket large expanses (e.g., snow, permafrost, and sea ice) or are concentrated in large volumes in specific locations (e.g., glaciers and ice sheets), lake and river ice are interwoven into the terrestrial landscape through the major freshwater flow and storage networks. In discussing the areal extent and volume of Arctic freshwater ice, it is important to note that the hydrological influence of this cryospheric component extends well outside the Arctic. For example, the major northward-flowing rivers of North America (Mackenzie) and Russia (Lena, $\mathrm{Ob}$, Yenisey) have their headwaters in more temperate latitudes, and ice-related effects in such locations have the potential to influence downstream Arctic environments.

In the case of river ice, Bennett and Prowse (2010) estimated that about $56 \%$ of the northern-hemisphere river network, extending southward to $33^{\circ} \mathrm{N}$ in North America and $27^{\circ} \mathrm{N}$ in Eurasia, experiences conditions conducive to some ice formation (Fig. 1). For large rivers in cold continental regions, such as the Lena and lower Mackenzie, or at high latitudes, such as the Yukon, ice conditions can persist for more than 6 months over the entire river length. By contrast, for rivers with more temperate headwaters, only sections (e.g., 73\% of Ob River length) experience such long-term ice effects. 


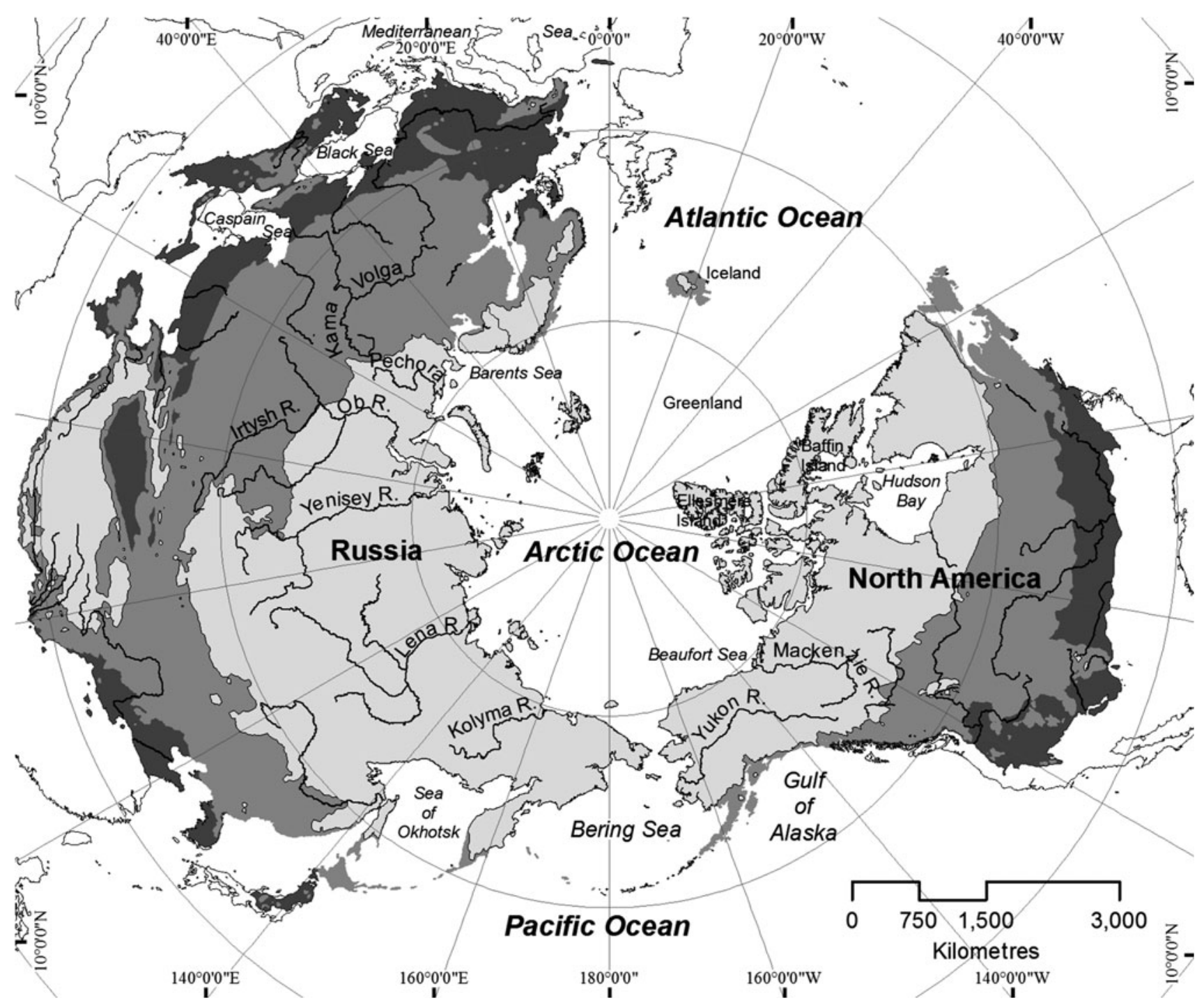

Fig. 1 Air-temperature based isotherm delineations of river ice regimes. Light gray depicts areas with more than 6 months ice cover, mid-gray those with approximately 3 months ice cover, and dark gray depicts those with transient ice effects. Source Bennett and Prowse (2010)

Most Arctic regions exhibit a substantial areal coverage by lakes of various types, their genesis and evolution largely dependent on components of the cryosphere, particularly glaciers, permafrost, and river ice (see Prowse et al. 2011b). The spatial extents of temporal ice regimes on such lakes are expected to be similar to those described for rivers. A large proportion of the above-noted regime classifications, however, are found outside the polar latitudes and, for the most part, lakes within these southern regions do not play a direct role in the Arctic. The exception would be lakes belonging to the hydrological networks draining to the Arctic.

In contrast to lakes, ice forms under much more dynamic conditions on rivers largely because of the hydraulic effects of flowing water (e.g., Beltaos and Prowse 2009). Once an ice cover is established, subsequent ice growth may be influenced by surface snow accumulation, which can act as an additional surface insulator and hence slow ice growth. It can, however, also promote the growth of surface ice through the formation of 'snow,' 'white,' or 'slush' ice, the process known as surface slushing. White ice currently tends not to be a major feature of Arctic conditions because snow loads are, for the most part, relatively small. As noted by Prowse et al. (2011a), this could change in the future and is important because of its strong effect on ice-surface and water-column radiation regimes.

As with freeze-up, the break-up of freshwater ice tends to be more dramatic on rivers than on lakes. Both ice covers go through a pre-breakup period of ablation: first losing surface layers of snow, then ice-surface melting, and in rivers, accelerated thinning of the ice bottom as flow velocities increase. At very high latitudes where the ice ablation season is short compared to the season for ice growth, freshwater ice on lakes may exist in a perennial form, developing only 
moats of summer meltwater. Freshwater ice can experience significant reductions in mechanical strength brought about by the internal absorption of solar radiation, particularly during the spring as incoming radiation seasonally increases and the highly reflective snow layers are ablated (e.g., Hicks et al. 2008). River water levels during spring break-up often far exceed those possible under open-water conditions at equivalent levels of discharge (see On-line Supplementary Material and Prowse et al. 2011b).

Surface-based observations have provided much of the information required to assess trends and variability regarding the response of lake and river ice to climate, the earliest long-term ice observations dating back to the 17th and 18th centuries. Over the past two decades, however, there has been a significant decline in a number of ice observations (Fig. 2). As reviewed in Prowse et al. (2011a), a number of other methods have been used, including isotopes, tree scars, and taxa buried in lake and pond sediments to extend the historical record. For several years, remote sensing has been seen as the technology that would eventually supersede surface-based observations of river and lake ice, but this has not yet been realized in any circumpolar country.

\section{CLIMATIC ROLE IN THE ARCTIC}

\section{Effects on Local Climate and Large-Scale Climatic Feedbacks}

In the Arctic, the meteorological and climatological effects of freshwater ice within the terrestrial landscape are mostly confined to the local scale, with the greatest effects produced by ice cover on large lakes. The presence or absence of ice directly modifies atmospheric heating of lakes and rivers through changes in latent and sensible heat fluxes, absorption and reflection of short-wave radiation, and longwave radiation emissivity of the surface. This in turn affects local climatic factors, primarily surface-air temperature, but also precipitation, evaporation, and low-level cloud cover. The degree to which the atmosphere is influenced depends on several factors including the magnitude, timing, location, and duration of ice cover (e.g., Rouse et al. 2005). Ice-covered freshwater bodies of various sizes represent a considerable fraction of the high-latitude, sub-Arctic and tundra landscape, and as such need to be considered in any type of climate modeling of Arctic terrestrial environments (e.g., Samuelsson et al. 2010). The lateral dimensions of large rivers can also approach those of small lakes, and the scale of their climatic impacts is likely comparable. The greatest effects are expected for the deltas of large river systems in which the network of tributary channels and interconnected ponds and lakes encompasses a vast region of the landscape. As a result, a significant shortening of the freshwater-ice duration period can have profound impacts on local, regional, and even large-scale climate over the Arctic (e.g., Rouse et al. 2005).

Climatic impacts from terrestrial water bodies are fairly well documented during open-water periods, but less is known regarding ice-covered conditions, with most information focusing on transitions in spring and autumn. During spring, an ice-covered water body has a significantly different energy balance to that of snow-free land, with near-shore zones usually characterized by cooler
Fig. 2 Historical evolution of the number of lake-ice and river-ice observation sites recorded in various databases. Data are from the Global Lake and River Ice Phenology Database (Benson and Magnuson 2007); the Canadian Ice Database (Lenormand et al. 2002); the Swedish Meteorological and Hydrological Institute (SMHI, provided by G. Weyhenmeyer); and the Russian State Hydrological Institute (provided by V. Vuglinsky; note the scale difference for this latter data set)

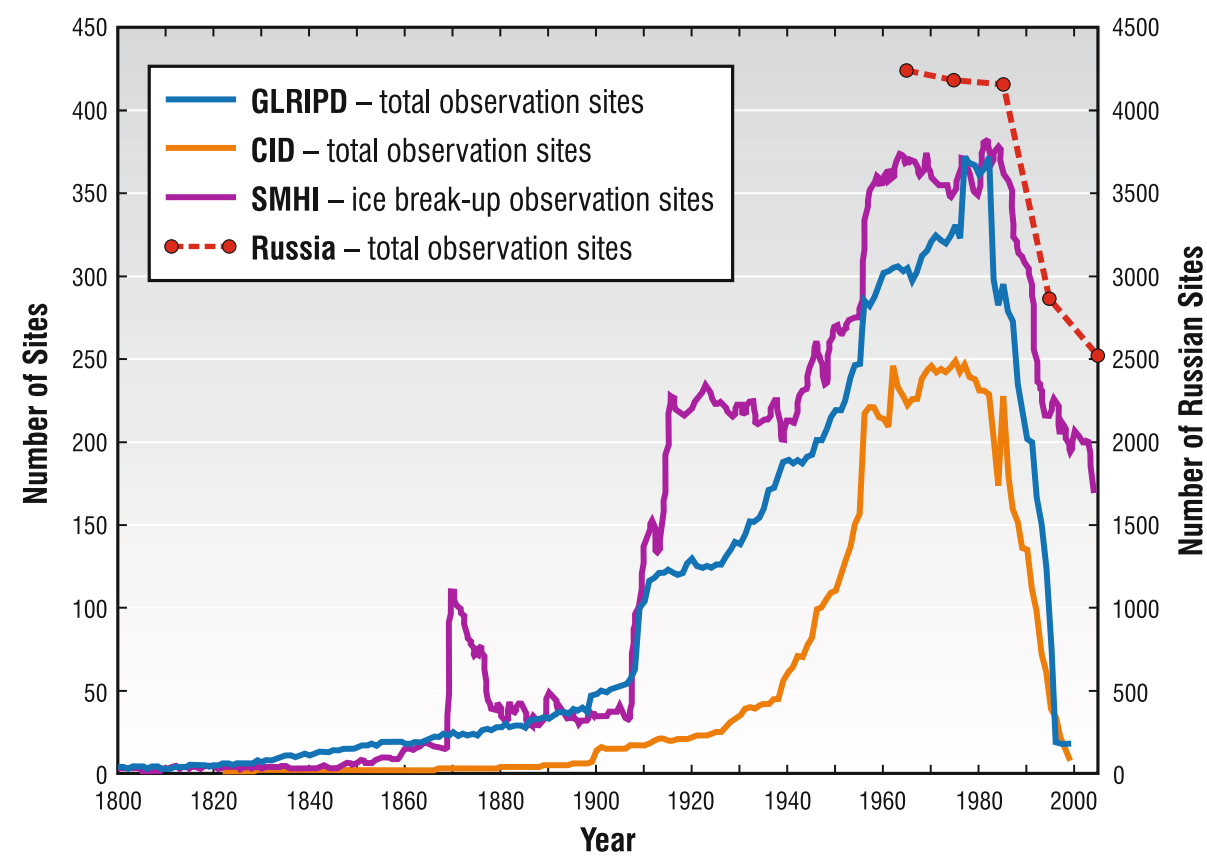

(C) Royal Swedish Academy of Sciences 2012 www.kva.se/en 
spring air temperatures. Studies have shown that the inclusion of lakes in numerical weather-prediction models can produce a springtime cooling of near-surface air temperature of up to several degrees Celsius in the vicinity of lakes when they are ice covered (e.g., Mackay et al. 2009). For large river deltas, ice break-up has been determined as the critical event impacting the thermal regime of local to regional climate. Arrival of the break-up front causes a rapid clearing of snow and ice leading to a dramatic reduction in surface albedo. During a dynamic break-up, local air temperatures have been found to rise rapidly, whereas thermal break-up (with less flooding) had minimal effects on surface temperature.

Regional to large-scale climatic feedbacks from freshwater bodies are mainly associated with big lakes and, to some degree, large river-delta systems. With regard to the former, modeling and observational studies revealed a significant enhancement of latent heat flux and suppression of sensible heat flux when freshwater lakes are present (e.g., Nagarajan et al. 2004; Rouse et al. 2005). One of the most comprehensive analyses related to freshwater-climate links in the Arctic was undertaken in the Mackenzie River Basin GEWEX (Global Energy and Water Cycle Experiment) Study. Results demonstrated that ice-cover duration and, to a lesser degree, ice thickness play significant roles in the annual energy and water balance of large river basins. This is mainly because ice cover prohibits evaporative exchange with the atmosphere for several months of the year. For large lakes, the evaporative and sensible heat fluxes reach their maxima during autumn and early winter mainly due to the greater frequency of cold air masses over relatively warm lake surfaces (Rouse et al. 2003). Such heat fluxes remain large as long as there is open water. For example, significant evaporation from Great Slave Lake occurs over a period ranging from 6 to 7 months (Blanken et al. 2007). Moisture from this evaporation can be an important source for subsequent precipitation within the Mackenzie River Basin (e.g., Szeto 2002). In fact, largelake evaporation in autumn and early winter is known to trigger frequent downwind snow squalls, as seen from passive microwave satellite images of the Great Slave Lake and Great Bear Lake region (similar to the Canadian Laurentian Great Lakes). Many of these findings from the Mackenzie GEWEX Study are also applicable to other circumpolar regions (Rouse et al. 2007).

High-latitude lakes are more prone to be affected by climate variability and change than the surrounding landscapes, mainly due to their strong absorption of solar radiation during the ice-free period. Therefore, shorter ice duration will act to increase annual net radiation, heat storage, and evaporative and sensible heat fluxes (Rouse et al. 2007). Such increases in net radiation will add to the heat content of the lake, as was shown for Great Slave Lake in the Mackenzie River Basin during the unusually warm year of 1998 when the ice-free period was about 40 days longer than normal (Schertzer et al. 2007). The larger heat storage will subsequently increase open-water evaporation and the overall sensible heat flux, particularly during autumn and early winter (for large lakes), which can then augment lake-effect snowfall by depositing more snow on downwind terrestrial locations.

\section{CLIMATIC CONTROLS ON FRESHWATER-ICE CHARACTERISTICS}

\section{Direct Controls}

The formation, growth, decay, and break-up processes of ice cover differ markedly between lakes and rivers, but all are influenced by similar climatic variables that control surface heat fluxes. River and lake size and depth have a strong effect on the timing of freeze-up, owing to the heat content of large water bodies. Freeze-up dates can vary by as much as 2 months between small and large lakes in the same region; however, size has no similar effect on breakup, which may only vary by about 2 weeks (Rouse et al. 2007). Air-temperature indices are often used for approximate prediction of ice-cover phenology and thickness (Borshch et al. 2001; Vuglinsky and Gronskaya 2006), but the resulting correlations are site-specific as they tacitly assume that all other relevant climatic variables are either constant or singly related to air temperature (Beltaos and Prowse 2009). Physically based process models quantify the synergistic effects of the relevant climatic variables, but may require specialized input data that are not always available (e.g., Saloranta and Andersen 2007). Prediction of break-up timing is hampered by knowledge gaps with respect to climatic effects on the composition of the ice cover, which partly controls internal decay by absorption of solar radiation (e.g., Hicks et al. 2008). Not only does ice composition differ between rivers and lakes, but it can also change during the ice season, thus, altering absorption characteristics (Walsh et al. 2005).

\section{Indirect Controls}

The mechanical action of wind and landscape hydrology can significantly affect ice timing and duration. Inflow from streams or land runoff can influence break-up, affecting the phenology by adding heat inputs, creating currents within the lake, or both. In the case of small lakes, for example, the spreading of spring meltwater on the surface can play an important role in decreasing surface albedo and, hence, indirectly advance the radiation decay of the ice cover (Grenfell and Perovich 2004). For large lakes, such processes are primarily limited to the margins 
where meltwater moats typically develop at the early stages of break-up or by the inflow of warmer water from rivers, which accelerates the break-up process. The largest indirect hydrological control relates to the volume and temperature of surface water and groundwater as these control the openwater heat budgets of lakes. The heat storage of lakes also greatly affects the timing of autumn freeze-up (e.g., Blanken et al. 2007). The duration of the ice-free period of summer warming is particularly important for stratified lakes where an earlier start to the stratified season can significantly increase the period over which a lake warms, leading to a greater increase in mean summer lake temperatures than would be expected simply from summer air temperatures (Austin and Colman 2007).

In rivers, the entire ice regime, including phenology, ice-cover thickness, and ice-jamming processes, is strongly influenced by hydrological variables, such as the flow regime and the base level, both of which are partly controlled by climate (Beltaos 2008a). For example, high autumn discharge tends to delay freeze-up, while high spring discharge tends to advance break-up and enhance the severity of ensuing ice jams and related flooding. The effects of discharge on river-ice processes arise from its controlling influence on flow hydrodynamics, including such variables as depth, velocity, erosional capacity, forces applied on the ice cover, and water surface slope. In terms of water surface slope, an additional influencing factor is the elevation of the water body into which a river may drain, such as another river, a lake, or the ocean. Complexity is further amplified by antecedent conditions (freeze-up levels and ice-cover thickness) playing a significant role in the timing and evolution of break-up events, which often generate extreme ice jams and floods. Although existing process-based modeling capability can largely account for many direct and indirect climatic effects, breakup-related phenomena have not yet been adequately quantified (Beltaos 2008b).

\section{CONCLUSIONS}

Lake and river ice are one of the most extensive cryospheric components of northern terrestrial landscapes, woven into the broad network of freshwater flow and storage systems, some of which have headwaters that originate at southerly latitudes well outside the Arctic. The state and fate of Arctic freshwater ice covers are therefore likely to be affected by other cryospheric components, some of which govern their genesis and temporal changes. Arctic freshwater ice both influences, and is influenced by various climatic conditions. Its effects are mostly local to regional in nature, but can be significant due to the large fraction of the northern high-latitude, sub-Arctic and tundra landscape occupied by freshwater, and by the abundance of large lakes and river deltas. Freshwater ice processes and phenologies are mainly impacted by the various climatic variables that control surface heat fluxes. However, landscape hydrology is also a major contributing factor. Despite the importance of freshwater ice to bio-physical and socioeconomic systems, there has been a recent reduction in observational recordings, although remote sensing still offers an opportunity to increase the spatial extent and temporal frequency of observations.

Acknowledgments The authors wish to thank the various national granting agencies that made this review possible, specifically including the Canadian Natural Sciences and Engineering Research Council, ArcticNet, and Environment Canada who helped directly support this publication. Also gratefully acknowledged are the efforts of the Arctic Monitoring and Assessment Program Secretariat in helping to produce the original SWIPA report and to the various contributing SWIPA chapter authors including: B. Bowden, V. Buzin, Y. Dibike, N. Gantner, L. Hinzman, L. Lia, T. Ouarda, R. Pienitz, J. Reist, M. Stickler, K.M. Walter Anthony, J. Weckström, and F. Wrona.

\section{REFERENCES}

AMAP. 2011. Snow, water, ice and permafrost in the Arctic (SWIPA). Oslo: Arctic Monitoring and Assessment Programme (AMAP).

Austin, J.A., and S.M. Colman. 2007. Lake Superior summer water temperatures are increasing more rapidly than regional air temperatures: a positive ice-albedo feedback. Geophysical Research Letters 34. doi:10.1029/2006GL029021.

Beltaos, S. 2008a. Onset of breakup. In River ice breakup, ed. Beltaos, S., 167-206. Highlands Ranch: Water Resources Publications.

Beltaos, S. 2008b. Challenges and opportunities in the study of river ice processes. Paper presented at "19th International ice symposium of IAHR", vol 1, pp. 3-27, July 6-11, in Vancouver, Canada.

Beltaos, S., and T. Prowse. 2009. River-ice hydrology in a shrinking cryosphere. Hydrological Processes 23: 122-144.

Bennett, K.E., and T.D. Prowse. 2010. Northern hemisphere geography of ice-covered rivers. Hydrological Processes 24: 235-240.

Benson, B., and J. Magnuson. 2007. Global lake and river ice phenology database. National Snow and Ice Data Center/World Data Center for Glaciology, Boulder, CO. Digital media. http://nsidc.org/data/g01377.html. Accessed 22 Oct 2010.

Blanken, P.D., W.R. Rouse, and W.M. Schertzer. 2007. The time scales of evaporation from Great Slave Lake. In Cold region atmospheric and hydrologic studies. The Mackenzie GEWEX experience, ed. Woo, M.-K., 181-196. Berlin: Springer-Verlag.

Borshch, S.V., B.M. Ginzburg, and I.I. Soldatova. 2001. Modeling the development of ice phenomena in rivers as applied to the assessment of probable changes in ice conditions at various scenarios of the future climate. Water Resources 28: 194-200.

Callaghan, T.V., M. Johansson, and T.D. Prowse eds. 2011. Arctic cryosphere-Changes and impacts, ed. T.V. Callaghan, M. Johansson, and T.D. Prowse. Ambio 40(S1). doi:10.1007/s13280011-0210-0. 
Grenfell, T.C., and D.K. Perovich. 2004. Seasonal and spatial evolution of albedo in a snow-ice-land-ocean environment. Journal of Geophysical Research-Oceans 109: 18.

Hicks, F., W. Cui, and G. Ashton. 2008. Heat transfer and ice cover decay. In River ice breakup, ed. Beltaos, S., 67-123. Highlands Ranch: Water Resources Publications, LLC.

Lenormand, F., C.R. Duguay, and R. Gauthier. 2002. Development of a historical ice database for the study of climate change in Canada. Hydrological Processes 16: 3707-3722.

MacKay, M.D., P.J. Neale, C.D. Arp, L.N.D. Domis, X. Fang, G. Gal, K.D. Johnk, G. Kirillin, et al. 2009. Modeling lakes and reservoirs in the climate system. Limnology and Oceanography 54: 2315-2329.

Nagarajan, B., M.K. Yau, and P.H. Schuepp. 2004. The effects of small water bodies on the atmospheric heat and water budgets over the MacKenzie River Basin. Hydrological Processes 18: 913-938.

Prowse, T.D., K. Alfredsen, S. Beltaos, B.R. Bonsal, C. Duguay, A. Korhola, J. McNamara, R. Pienitz, et al. 2011a. Past and future changes in Arctic lake and river ice. In Arctic cryosphereChanges and impacts, ed. T.V. Callaghan, M. Johansson, and T. Prowse. Ambio 40(S1). doi:10.1007/s13280-011-0216-7

Prowse, T.D., K. Alfredsen, S. Beltaos, B. Bonsal, W.B. Bowden, C. Duguay, A. Korhola, J. McNamara, et al. 2011b. Effects of changes in arctic lake and river ice. In Arctic cryosphereChanges and impacts, ed. T.V. Callaghan, M. Johansson, and T. Prowse. Ambio 40(S1). doi:10.1007/s13280-011-0217-6

Rouse, W.R., C.M. Oswald, J. Binyamin, P.D. Blanken, W.M. Schertzer, and C. Spence. 2003. Interannual and seasonal variability of the surface energy balance and temperature of central Great Slave Lake. Journal of Hydrometeorology 4: 720-730.

Rouse, W.R., C.J. Oswald, J. Binyamin, C.R. Spence, W.M. Schertzer, P.D. Blanken, N. Bussieres, and C.R. Duguay. 2005. The role of northern lakes in a regional energy balance. Journal of Hydrometeorology 6: 291-305.

Rouse, W.R., P.D. Blanken, C.R. Duguay, C.J. Oswald, and W.M. Schertzer. 2007. Climate-lake interactions. In Cold region atmospheric and hydrologic studies. The Mackenzie GEWEX experience, ed. Woo, M.-K., 139-160. Berlin: Springer-Verlag.

Saloranta, T.M., and T. Andersen. 2007. MyLake-A multi-year lake simulation model code suitable for uncertainty and sensitivity analysis simulations. Ecological Modelling 207: 45-60.

Samuelsson, P., E. Kuorzeneva, and D. Mironov. 2010. The impact of lakes on the European climate as simulated by a regional climate model. Boreal Environment Research 15: 113-129.

Schertzer, W.M., W.R. Rouse, P.D. Blanken, A.E. Walker, D. Lam, and L. León. 2007. Interannual variability in heat and mass exchange and thermal components of Great Slave Lake. In Cold region atmospheric and hydrologic studies. The Mackenzie GEWEX experience, ed. Woo, M.-K., 197-219. Berlin: Springer-Verlag.

Szeto, K.K. 2002. Moisture recycling over the Mackenzie basin. Atmosphere-Ocean 40: 181-197.

Vuglinsky, V.S., and T.P. Gronskaya. 2006. Changing of rivers and lakes ice regime within the Russian territory and their possible consequences for economy. Modern problems of hydrometeorology, 229-245. Asterion: St. Petersburg (in Russian).

Walsh, J.E., O. Anisimov, J.O.M. Hagen, T. Jakobsson, J. Oerlemans, T.D. Prowse, V. Romanovsky, N. Savelieva, et al. 2005. Cryosphere and hydrology. In Arctic climate impact assessment, ed. Arris, L., 183-242. Cambridge: Cambridge University Press.

\section{AUTHOR BIOGRAPHIES}

Terry Prowse $(\square)$ is a senior Research Scientist with Environment Canada and a Professor in the Department of Geography at the University of Victoria. His research focuses on the effects of climate variability and change on cold-regions hydrology, hydro-climatology, and hydro-ecology.

Address: Department of Geography, Environment Canada, University of Victoria, Victoria, BC V8P 5C2, Canada.

e-mail: terry.prowse@ec.gc.ca

Knut Alfredsen is a Professor in hydrology at the Norwegian University of Science and Technology. His main research interests include river ice, cold climate ecohydrology, and environmental impacts of hydropower.

Address: Department of Hydraulic and Environmental Engineering, NTNU, 7491, Trondheim, Norway.

e-mail: knut.alfredsen@ntnu.no

Spyros Beltaos is a senior Research Scientist at the National Water Research Institute of Environment Canada and an Adjunct Professor at the Department of Geography, University of Victoria. His research interests include hydroclimatic and ecological impacts of ice processes in northern rivers and deltas, with emphasis on breakup and ice jams.

Address: Aquatic Ecosystem Impacts Research Division, Environment Canada, National Water Research Institute, 867 Lakeshore Rd., Burlington, ON L7R 4A6, Canada.

e-mail: spyros.beltaos@ec.gc.ca

Barrie Bonsal is a Research Scientist with Environment Canada where he specializes in the assessment of past and projected future climatological impacts on the hydrology and ecology of Canada and the Northern Hemisphere.

Address: Environment Canada, National Hydrology Research Centre, 11 Innovation Blvd, Saskatoon, SK S7N 3H5, Canada.

e-mail: barrie.bonsal@ec.gc.ca

Claude Duguay is a Professor in the Department of Geography \& Environmental Management and Founding Director of the Interdisciplinary Centre on Climate Change at the University of Waterloo. His research interests include climate-lake interactions, remote sensing and numerical modeling of the cryosphere, and northern hydrology.

Address: Department of Geography \& Environmental Management, University of Waterloo, 200 University Avenue West, Waterloo, ON N2L 3G1, Canada.

e-mail: crduguay@uwaterloo.ca

Atte Korhola is a Professor of environmental change at the University of Helsinki and a member of the Environment Panel of the European Academies Science Advisory Council (EASAC). His specialist research interests include climate change and its ecological and societal impacts with particular reference to longer term environmental changes and northern regions.

Address: Department of Environmental Sciences, ECRU, University of Helsinki, P.O. Box 65 (Viikinkaari 1), Helsinki 00014, Finland. e-mail: atte.korhola@helsinki.fi

Jim McNamara is a Professor of hydrology at Boise State University in Boise Idaho, USA. His research interests include interactions between catchment hydrologic, geomorphologic, and biologic processes in cold regions.

Address: Boise State University, 1910 University Dr., Boise, ID 83703, USA.

e-mail: jmcnamar@boisestate.edu

Warwick F. Vincent is a Professor of biology and Canada Research Chair at Laval University, Canada, where he is also director of the Centre for Northern Studies (CEN), an inter-interuniversity centre of excellence for research on northern ecosystems and geosystems. He 
works on the effects of environmental change on polar aquatic ecosystems.

Address: Département de Biologie \& Centre d'Études Nordiques (CEN), Laval University, Québec City, QC G1V 0A6, Canada.

e-mail: warwick.vincent@bio.ulaval.ca

Valery Vuglinsky is a Professor and Deputy Director for Science at the State Hydrological Institute in the Russian Federation; he is also Head of Hydrology Department at St. Petersburg State University. His main research interests include: water resources and water balance, hydrology of lakes and reservoirs, water resources inventory and hydroecology.
Address: State Hydrological Institute, 2nd Line 23, 199053 St. Petersburg, Russian Federation.

e-mail: vvuglins@vv4218.spb.edu

Gesa A. Weyhenmeyer is an Associate Professor and Senior Lecturer at Uppsala University and the Swedish University of Agricultural Sciences. She is presently a Research Fellow Post at the Royal Swedish Academy of Sciences and focuses her research on global change impacts on aquatic ecosystems.

Address: Department of Ecology and Genetics/Limnology, Uppsala University, Norbyvägen 18D, SE 75236 Uppsala, Sweden.

e-mail: gesa.weyhenmeyer@ebc.uu.se 